\title{
The Costs and Benefits of Investing in Universal Preschool: Evidence From a Spanish Reform
}

\author{
Thomas van Huizen iD \\ Utrecht University
}

\author{
Lisa Dumhs \\ Utrecht University and UWV
}

\author{
Janneke Plantenga \\ Utrecht University
}

\begin{abstract}
This study provides a cost-benefit analysis of expanding access to universal preschool education, focusing on a Spanish reform that lowered the age of eligibility for publicly provided universal preschool from age 4 to age 3. Benefits in terms of child development and maternal employment are estimated using evidence on the causal effects of this reform. In the baseline estimation the benefit-cost ratio is over 4, indicating sizeable net societal benefits of the preschool investment. The results show that the child development effects are the major determinant of the cost-benefit ratio; the employment gains for parents appear to play a relatively minor role. Overall, the cost-benefit analysis provides support for investing in high-quality preschool education.
\end{abstract}

The large majority of children in developed countries participate in Early Childhood Education and Care (ECEC) before entering primary school (Eurostat, 2016; OECD, 2017b). Several European countries (e.g., Norway, France, and Spain) offer universal preschool services to children aged 3 and older, and in many European countries, almost all 4- and 5-year-olds participate in ECEC. While preschool enrollment rates are generally lower in the United States, a number of states (e.g., Oklahoma, Georgia) as well as cities (e.g., New York City) have implemented universal preschool systems. As these services are (partially) publicly funded, public spending on ECEC is substantial with $0.7 \%$ of gross domestic product (GDP) on average across OECD countries (OECD, 2017a).

There are two main (efficiency) arguments that justify these public investments in ECEC. First, investments in ECEC may improve child development: Various scholars claim that (high-quality) ECEC improves school readiness, increases children's performance in school, and positively affects a wide range of relevant outcomes in adulthood (Barnett, 2011; Duncan \& Magnuson, 2013; Elango, Garcia, Heckman, \& Hojman, 2015; Gormley,

This research was supported by a European Union grant for the CARE project (Grant 613318).

Correspondence concerning this article should be addressed to Thomas van Huizen, Utrecht School of Economics, Utrecht University, PO Box 80125, 3508 TC Utrecht, The Netherlands. Electronic mail may be sent to t.m.vanhuizen@uu.nl.
Gayer, Phillips, \& Dawson, 2005; Reynolds \& Ou, 2011). Second, investments in ECEC may increase parental employment: Available and affordable child-care services allow parents to return to work after a period of leave and are therefore frequently considered as important determinants of high (female) employment rates (Attanasio, Low, \& Sanchez-Marcos, 2008; Jaumotte, 2003).

Given the growing importance of ECEC in terms of public spending and the widely supported efficiency arguments, this study examines to what extent the benefits for children and parents outweigh the public investments in universal preschool, focusing on the Spanish Ley Orgánica de Ordenación General del Sistema Educativo (LOGSE) reform in the early 1990s. Most of the existing evidence on the cost-effectiveness of ECEC programs concerns programs targeted at disadvantaged children (e.g., Barnett \& Masse, 2007; Belfield, Nores, Barnett, \& Schweinhart, 2006; Heckman, Moon, Pinto, Savelyev, \& Yavitz, 2010; Lynch, 2004; Reynolds, Temple, White, Ou, \& Robertson, 2011; Temple \& Reynolds, 2007; WSIPP, 2014). Overall, the results of cost-benefit analyses (CBAs) of these targeted interventions are encouraging: For instance, every dollar invested in the High/Scope Perry Preschool Program generates a total return to society of

(C) 2017 The Authors

Child Development (c) 2017 Society for Research in Child Development, Inc. All rights reserved. 0009-3920/2019/9003-0029

DOI: $10.1111 /$ cdev.12993 
7-12 dollars. Similar benefit-cost ratios are found for the Carolina Abecedarian Project (ABC; 7.3; García, Heckman, Leaf, \& Prados, 2016) and the preschool program of the Chicago Child-Parent Centers (CPC; 10.8; Reynolds et al., 2002; 2011).

While there is a growing amount of evidence concerning targeted programs, there is still little evidence on the cost-effectiveness of expanding universal access to ECEC. Several studies rely heavily on the evidence for these targeted programs to predict the economic returns of universal programs (e.g., Aguirre et al., 2006; Karoly \& Bigelow, 2005; Lynch, 2007; Lynch \& Vaghul, 2015; see Karoly, 2016 for a recent overview). However, an important drawback of these ex ante evaluations is that the results of targeted programs have limited applicability to universal programs: there may be important differences in the programs offered (and the associated costs) as well as the enrolled population of children (i.e., general population in universal programs vs. disadvantaged children in targeted programs). Given these fundamental differences, the ex ante evaluations of universal programs are based on strong (and sometimes rather arbitrary) assumptions about the likely effects of universal programs. For instance, Karoly and Bigelow (2005, p. xxii) project the benefits of the introduction of a high-quality preschool program in California and base their estimates on the CPC program results, ". . . we assume high-risk children who move from no preschool to preschool would experience 100\% of the CPC program gains, while medium- and low-risk children would experience $50 \%$ and $25 \%$ of the CPC program gains, respectively." In a similar CBA (for the entire United States), Lynch and Vaghul (2015) also convert the CPC effects into effects for all children but make somewhat different assumptions about the effects for middle and upper income children.

Evidence on the cost-effectiveness of public investments in universal ECEC that is based on causal evidence (i.e., impacts from the program itself) is virtually nonexistent. An important reason for this is that universal ECEC programs cannot be evaluated by randomized controlled trials (RCTs) and estimating the causal impact of ECEC programs on child development and maternal employment is challenging due to endogeneity issues. Specifically, parents and children do not randomly select into ECEC services and therefore it is likely that there are (unobservable) differences between users and nonusers. These (unobserved) differences may be related to child development and to the employment probability of mothers. When these issues are not adequately taken into account, the estimated relations - and therefore the level of the monetized benefits-are biased. In order to deal with this methodological problem, scholars have exploited natural experiments, generally based on policy reforms (e.g., largescale expansions) or specific institutional features (e.g., age eligibility cutoffs), to estimate the causal effects of universal ECEC on child development (Berlinski et al., 2009; Havnes \& Mogstad, 2011b; Van Huizen \& Plantenga, 2015) and maternal employment (e.g., Cascio, 2009; Havnes \& Mogstad, 2011a).

The aim of the current study is to evaluate the cost-effectiveness of a universal preschool program using evidence from a natural experiment. As natural experiments allow for a stronger claim of causality, we consider this a promising strategy. However, CBAs that follow this strategy are scarce. To our knowledge, only two studies are available that have followed this approach. Applying a regression discontinuity approach, Bartik, Gormley, and Adelstein (2012) estimate the short-run effects of the Tulsa universal pre-K program on cognitive test scores and translate these effects into gains in children's lifetime earnings. A potential problem is that the projection of the benefits relies on the assumption that the child development effects are persistent, while evidence suggests that these shortterm cognitive gains may fade out (e.g., Barnett, 2011; Duncan \& Magnuson, 2013). Karoly (2016, p. 50) points out this limitation of relying on estimates on short-term gains, "... the fact that preschool participants' short-term developmental or achievement test gains may not last ... raises the question of whether we can use such short-term gains to forecast." Indeed, the fade-out potential introduces a type of uncertainty in the projections of the benefits (e.g., in terms of lifetime earnings) that is difficult to account for in the analysis. This problem is confirmed by the second study that provides a (short, partial) CBA based on a natural experiment: Cascio and Schanzenbach (2013, pp. 171174) apply a difference-in-differences (DD) approach to estimate the fourth and eighth grade test score impacts of the Georgia and Oklahoma universal preschool programs and use these estimates to predict children's lifetime earnings benefits. However, due to the fading out of the effect and the lack of precision of the estimates (overall effects on eighth grade scores are insignificant), the benefits are highly uncertain. Hence, in both studies the estimates of the benefits are associated with considerable uncertainty. Furthermore, it should be noted that the studies only provide a 
partial CBA, as they do not take into account benefits for parents.

Given this state of affairs, this study provides the first causal evidence-based CBA of universal preschool for Europe, by analyzing the Spanish LOGSE reform. This national reform, implemented in the early 1990s, lowered the age of universal eligibility for publicly subsidized preschool from age 4 to age 3 . The reform provides an interesting case for cost-benefit analysis of universal ECEC for several reasons. First, it represents a rare case in which the effects of a natural experiment on both child development and maternal employment have been identified: Nollenberger and Rodríguez-Planas (2015) and Felfe, Nollenberger, and Rodríguez-Planas (2015) examined the impact of LOGSE on the employment rate of mothers and the cognitive development of children, respectively. Second, to estimate lifetime earnings gains for children, we use evidence on long-term (age 15) rather than shortterm effects on cognitive achievement. Compared to estimates of short-term (potentially fading out) cognitive gains, the results on these persistent gains can be more reliably used to predict gains in lifetime earnings. Third, because the estimated effect sizes are consistent with the overall findings in the recent natural experiment literature (see following), the case provides some general lessons on the costeffectiveness of universal preschool. Finally, also from a costs perspective, the Spanish reform represents a rather general case. Although the program is sometimes considered as a relatively high-quality program (e.g., Felfe et al., 2015), the program is not exceptionally expensive. In fact, the costs per child are comparable to some U.S. state preschool programs (see following) and therefore the program seems a feasible policy option for most developed countries. This is crucial for CBA as the central question is whether and to what extent the benefits outweigh the costs. Targeted programs may generate relatively large effects (in terms of child outcomes), but are generally offered at higher costs too. Our cost-benefit analysis therefore aims to contribute to understanding the general dilemmas and challenges of expanding universal ECEC.

\section{Method}

\section{The LOGSE Reform}

In 1990, Spain implemented a major educational reform: the LOGSE. This reform had an impact on the organization of the entire education system, ranging from preschool to high school. For this study, we are mainly concerned with the impact of the LOGSE reform on preschool arrangements (see for more details Felfe et al., 2015; Nollenberger \& Rodríguez-Planas, 2015). According to the LOGSE, early childhood education ("educación infantil") consists of two phases: the period from birth to age 3 and the period from ages 3 to 6 (the school starting age).

Before the LOGSE reform, children of 4 and 5 years of age were covered by free universal public preschool education. The reform increased the eligibility of preschool services to 3-year-olds, leading to a dramatic increase in public preschool enrollment rates (from $8.5 \%$ in 1990 to $42.9 \%$ in 1997 and to $67.1 \%$ in 2002). Preschools were generally integrated within primary schools and children are grouped in classes by age. Preschools had the same hours as compulsory schools. The preschool program was based on a full-day schedule, typically 9 a.m. to 5 p.m. on workdays (except for a total of 14 weeks of school vacation per year).

The reform not only increased the availability of preschool services for 3-year-olds, but also had an impact on the quality of the service by regulating educational content, group size, and the educational requirements of the staff. In terms of structural aspects of quality, under the new system, preschool teachers of 3-year-olds were required to have a college degree in pedagogy and the maximum class size was set at 20 for 3-year-olds (instead of 25 for 4- and 5-year-olds). In terms of educational content, national regulations describe general preschool objectives and set requirements for curricula. Constructivism and progressive education formed the theoretical basis for the development of national curriculum guidelines.

The new curriculum guidelines were organized into three areas of experience: communication and representations, knowledge of the physical and social world, and personal autonomy and identity (Tietze, Hundertmark-Mayser, \& Rossbach, 1999). This represents a clear movement away from traditional Spanish preschool practices, which have a strong focus on individual seatwork due to the fact that most preschools were developed as a downward extension of primary schools.

While quality standards improved and the Spanish preschool program is sometimes described as "high quality" (e.g., Felfe et al., 2015), there seems to be considerable variation in quality levels and there appears to be significant room for improvement in quality overall. First, while overarching national regulations specify minimum 
requirements and the Ministry of Education has to safeguard a certain level of homogeneity of preschool programs, substantial variation in program quality exists. Spain is a highly decentralized unitary state consisting of 17 autonomous communities which have authority over the policy area of education. This implies, for instance, that the autonomous communities can further specify the requirements of curricula and determine how these curricula are evaluated. This explains, for example, why preschool quality is comparatively low in Seville, capital of the relatively poor region Andalusia (Palacios, Lera, \& Oliva, 1995). Second, comparing process quality levels between Spain, Portugal, Germany, and the United States, Spanish preschools appear to score rather low on the Early Childhood Environment Scale, but high on the Caregiver Interaction Scale (though differences between countries are generally not statistically significant; Cryer, Tietze, Burchinal, Leal, \& Palacios, 1999). Given the (regional) variation in quality levels and the fact that Spain does not score unambiguously high in the comparative quality assessment, we do not consider this as a "model" program or best practice.

When the reform took place, female labor market participation in Spain was low: $34 \%$ of all women were active on the labor market, considerably below the EU average of $46 \%$. Unemployment rates were high (around 20\%) and average unemployment duration was about 2 years. The use of child care and preschool for 3-year-olds was limited because of a lack of supply and a mismatch between supply and demand. Possibilities to adjust working hours were rare: part-time employment was virtually nonexistent in Spain and there were limited possibilities to vary start and end times of work for family reasons (Mills et al., 2014). In effect, only approximately $10 \%$ of the youngest age group (0-4) made use of childcare facilities. In short, the Spanish case concerned a reform of a public ECEC system with low (initial) coverage rates against a background of a slack labor market, limited possibilities for family work reconciliation, and low levels of female labor force participation.

\section{Estimated Effects of the Spanish Preschool Expansion}

\section{Identification Strategy}

To identify the causal effects of the LOGSE reform on maternal employment and child development,
Nollenberger and Rodríguez-Planas (2015) and Felfe et al. (2015) exploit variation in the speed of expansion between regions using a DD approach. Such a DD approach has been applied in various other studies on this topic (Bauernschuster \& Schlotter, 2015; Cascio \& Schanzenbach, 2013; Havnes \& Mogstad, 2011a, 2011b) and allows for a relatively strong claim of causality (see Angrist \& Pischke, 2008 for a methodological discussion of the DD approach). In the Spanish case, the variation in the speed of expansion varied substantially between regions: in high-intensity regions, the public preschool coverage rate increased from $<10 \%$ to $44 \%$ during the 3 years after the introduction of the reform, whereas in that same period the coverage rate rose from 7.4 to $15.3 \%$ in low-intensity regions (Felfe et al., 2015, pp. 400-401). Interestingly, the enrollment of 3-year-olds in private child care followed the same trend in high-intensity and low-intensity regions (both experienced a slight increase in the 1987-2002 period), indicating that the increase in public enrollment did not crowd out private preschool. Moreover, Felfe et al. (2015) argue that the additional public preschool places substituted mainly for parental care rather than informal child care as most children of working mothers were enrolled in formal (public and private) care in the pre-reform period. Table 1 provides an overview of the estimated effects on child development and maternal employment (including the $90 \%$ confidence interval). Next, we discuss these estimates in more detail.

\section{Child Development}

Using the 2000-2009 waves of the Programme for International Student Assessment (PISA), Felfe et al. (2015) estimated the effects of the Spanish preschool expansion on long-term child development (evidence on the short-term effects is not available). According to their preferred specification, the reform increased age 15 reading scores of students in high-intensity regions relative to low-intensity regions by 0.154 SDs. However, the reform had no significant effect on children's math achievement. Felfe et al. (2015, p. 411) argue this is in line with the expectations because "activities undertaken in public child care stimulate children's social and emotional competencies and thus their language and reading skills but not necessarily their math skills." In addition, the results also indicate a decline of 2.4 percentage points in the grade retention rate during primary education. Compared to the pre-reform situation, 
Table 1

Summary of the Main Difference-in-Differences Results

\begin{tabular}{|c|c|c|c|c|c|c|}
\hline Beneficiary & Domain & Effect size & Standard error & $\begin{array}{l}\text { Lower bound } \\
\qquad(90 \% \mathrm{CI})\end{array}$ & $\begin{array}{l}\text { Upper bound } \\
\text { (90\% CI) }\end{array}$ & $N$ \\
\hline $\begin{array}{l}\text { Mother (Nollenberger \& } \\
\text { Rodríguez-Planas, 2015) }\end{array}$ & Employment & $0.181(0.028)$ & $0.103(0.016)$ & $0.011(0.004)$ & $0.350(0.0537)$ & 105,748 \\
\hline \multirow[t]{4}{*}{ Child (Felfe et al., 2015) } & PISA reading score & $0.5969(0.1540)$ & $0.2597(0.0670)$ & $0.1697(0.0438)$ & $1.0241(0.2642)$ & 40,340 \\
\hline & PISA math score & ns & - & - & - & 38,091 \\
\hline & $\begin{array}{l}\text { Grade retention } \\
\text { primary school }\end{array}$ & $0.0932(0.0240)$ & $0.0504(0.013)$ & $0.0101(0.0026)$ & $0.1759(0.0454)$ & 20,458 \\
\hline & $\begin{array}{l}\text { Grade retention } \\
\text { secondary school }\end{array}$ & $n s$ & - & - & - & 20,458 \\
\hline
\end{tabular}

Note. Effect sizes are presented as treatment-on-the-treated (intention-to-treat between parentheses): the effect per additional 3-year-old child in public preschool. The employment effect is expressed in additional mothers in employment per additional child in preschool. The effects on Programme for International Student Assessment (PISA) reading scores are expressed in percentage change in standard deviations of the achievement scores.

this implies a decrease in the incidence of retention of almost $50 \%$.

As in most DD studies, the effects presented by Felfe et al. (2015) are reported as intention-totreat (ITT) effects, comparing all (not just those enrolled in preschool) children in low-intensity regions with children in high-intensity regions. Following the DD literature (e.g., Baker, Gruber, \& Milligan, 2008; Cascio \& Schanzenbach, 2013; Havnes \& Mogstad, 2011b), we calculate the treatment-on-the-treated (TOT) effect by dividing the ITT parameter by the relative increase in public preschool coverage in the high-intensity versus the low-intensity area (25.8\%; see Felfe et al., 2015, p. 410). Accordingly, the TOT with respect to PISA reading scores is $(0.154 / 0.258=) 0.5969$. Given that Felfe et al. (2015) find no significant effect on math scores, for our cost-benefit analysis we assume a zero effect on this domain. Finally, the TOT with respect to grade retention is $(-0.024 / 0.258=)$ -0.093 .

The TOT effects capture, in principle, the effect of enrollment in the relatively high-quality (postreform) preschool program. The effects can be fully attributed to the increase in enrollment when there would be no difference in the prereform coverage rate between low- and highintensity regions and/or when there would be no significant change in quality (see Appendix S1). However, the pre-reform coverage rate was slightly higher in high-intensity regions and the Spanish reform involved a quality improvement. It is plausible that a fraction of the total reform effect (captured by the ITT parameter) is the result of an increase in preschool quality, given the differences in pre-reform coverage rates. That is, even if preschool had not expanded, skills may have improved more in high-intensity regions compared to low-intensity regions as preschool quality improvements affect a larger share of children in high-intensity regions. This implies that we may overestimate the TOT effect. However, given that the difference in pre-reform coverage $(2.5 \%)$ is small compared to the relative increase in coverage $(25.8 \%)$, we can demonstrate that it is likely that the TOT effect is only marginally overestimated (see Appendix S1). Even if the TOT effect of attending pre-reform quality level preschool were zero and all positive effects were driven by the preschool quality improvement, the TOT effect of attending postreform quality level preschool would be 0.5442 instead of 0.5969 (i.e., an overestimation of $<10 \%$ ). We therefore argue that the estimated effects are almost completely driven by the increased enrollment in the new (higher quality) preschool program.

Furthermore, it should be noted that our TOT parameter also captures peer effects and may therefore be an overestimation of the average effect of treatment (enrollment) for the individual child if there are positive spillover (peer) effects. As the TOT parameter is derived from the ITT effect, which captures the complete impact of the expansion, the TOT parameter includes, in addition to the individual treatment effect, the average peer effect on children who did not participate in preschool at age 3. Because peer effects are likely to be relevant (especially in the case of universal preschool [Cascio, 2017]), this is an important advantage of our approach compared to CBAs based on RCT (which do not include peer effects). 
Although it may in general be difficult to compare effect sizes across studies, it seems that the TOT skills effect size based on the LOGSE reform is in line with the existing literature. The TOT effect size for reading skills of close to $0.6 S D$ and a zero effect for math skills implies a weighted average relevant for our CBA of $0.26 S D$ (see following). Interestingly, for the cognitive domain the average effect size in U.S. studies is close to 0.3 SD (in highquality research designs, measured at age older than 10) and around $0.35 S D$ in non-U.S. studies (Barnett, 2011).

\section{Maternal Employment}

Nollenberger and Rodríguez-Planas (2015) follow a similar strategy to estimate the maternal employment effect of offering free public preschool for 3-year-olds. In addition to the speed of expansion, they compare in a DD-in-differences (DDD) approach mothers whose youngest child is 3 years old (treatment group) with mothers whose youngest child is 2 years old (control group). Their DDD estimates indicate that the reform increased maternal employment by 2.8 percentage points $(9.6 \%)$. As the relative increase in preschool enrollment among 3-year-olds (compared to 2-year-olds) was $15.5 \%$, this ITT effect implies a TOT of $0.181(=0.028 / 0.155)$. Hence, for 10 additional children aged 3 in preschool, approximately two mothers took up employment (see also Nollenberger \& Rodríguez-Planas, 2015, p. 133). Given that public preschool mainly substituted for maternal care, this effect may seem rather modest. The authors attribute this relatively small employment effect to the Spanish labor market conditions during this time period in general and to the family-unfriendly working conditions in particular.

Comparing the results of Nollenberger and Rodríguez-Planas (2015) with other recent evidence, the employment-to-enrollment ratio of nearly 0.2 seems to be more or less average, between the relatively low employment-to-enrollment ratios (e.g., 0.06 for Norway Havnes \& Mogstad, 2011a) and the relatively high estimates (e.g., 0.37 for Germany Bauernschuster \& Schlotter, 2015, and around 0.4 for single mothers in the United States Cascio, 2009). The effect on maternal employment is relatively imprecisely estimated and the $90 \%$ confidence interval includes almost the entire range of estimates reported in the recent natural experiment literature. Using these as lower and upper bounds in our analysis, we demonstrate to what extent our results are sensitive to the size of the maternal employment effect.

\section{CBA: General Approach}

In our cost-benefit analysis, we distinguish between three groups of beneficiaries of the Spanish ECEC reform: parents (mothers), children, and taxpayers (the general public). We estimate how the causal effects (summarized in Table 1) translate into higher lifetime earnings of parents and children. Parents have gained from the LOGSE preschool expansion as it allowed mothers to stay employed after childbirth, thereby positively affecting their earnings. Moreover, as mothers were able to stay active or return to work sooner, the reform had a positive effect on their human capital and thereby on maternal earnings in the longer term. Children have benefited from the preschool reform due to improved skill levels (and reduced grade retention), which will translate into higher expected lifetime earnings. Finally, taxpayers gain as gross lifetime earnings of mothers and children increase. Since additional taxes on earnings are "derived" benefits, taxes only affect the distribution and not the size of the total level of benefits to society. In addition to increased taxes on earnings, taxpayers also benefit from the reduction in primary school grade retention, as this will decrease public expenditure on education.

The main challenge in our analysis is to quantify the benefits for parents, children, and taxpayers into (monetary) present value terms. As stated earlier, existing CBAs are mainly based on RCTs of targeted ECEC interventions (e.g., García et al., 2016; Heckman et al., 2010; Reynolds et al., 2011). These RCTs provide TOT estimates of the effects of the program, which are used to estimate the benefits of the ECEC program. We follow this approach and use the TOT effects in our costbenefit analysis, using 1997 as base year. Hence, we compare the costs of one additional 3-year-old in preschool with the average benefits gained by improving the cognitive skills of a 3-year-old plus the average benefits gained by encouraging the employment of mothers. This strategy allows us to estimate the benefit-cost ratio of the investment, and the results provide insights into whether the ECEC investment pays off: How many dollars (in present value terms) does society receive back for each dollar invested in ECEC? Moreover, the analysis indicates the main benefits, the main beneficiaries, and the sensitivity of the results to specific parameters. 
As discussed earlier, all the benefits for children and some of the benefits for parents materialize in the future (from the perspective of the investment year). The benefits are expressed in real dollars $(\$ 1=€ 0.88)$, using 1997 as the base year. Following previous CBAs of targeted ECEC interventions (Heckman et al., 2010; Nores, Belfield, Barnett, \& Schweinhart, 2005; Reynolds et al., 2011), we calculate the present value of these future streams of benefits using a 3\% discount rate. We assess to what extent the main results are sensitive to the specific discount rate.

\section{Costs of Universal Preschool}

In CBAs of RCTs, costs per child can relatively easily be calculated as the total program costs divided by the number of participants. Estimating the additional costs per child of large-scale (nationwide) expansions is generally more difficult. A potential problem is that the additional costs per child due to the reform are not necessarily equal to the average (postreform) costs per child. However, we can demonstrate (see Appendix S2) that, in the case of the Spanish ECEC expansion, we can approximate the reform costs per child to the costs per child in the postreform period.

In the Spanish case, data on the cost per child of public preschool education in Spain in the relevant time period are not available in international or Spanish public data sets. Based on data from the Spanish Ministry of Education, Nollenberger and Rodríguez-Planas (2015) and Felfe et al. (2015) estimate that in 1997, annual expenditure per child was $\$ 2,733$ (€2,405). However, as not all expenditures are included (e.g., infrastructure costs), this is likely to be an underestimation of the actual costs. Furthermore, about one of three children are enrolled in private (pre)schools, which are only partially publicly funded. Public spending per child (based on all children) is therefore lower than the public spending per child in a public school.

Given these issues, we base our estimate of the cost per child on the 2007 estimates of the annual public expenditure per child provided by RogeroGarcía and Andrés-Candelas (2014). We use the OECD consumer price index (CPI) to account for inflation and estimate the 1997 cost per child. We calculate the cost per child in preschool as the cost for preschool and primary education (one expenditure category) associated with teaching activities plus the average additional costs per child (excluding spending on "scholarships and grants for textbooks and material"). Accordingly, the total cost per child in preschool is $\$ 4,027$ (€3,544; $€ 4,762$ in 2007 prices). Interestingly, based on an alternative source (European Commission, EACEA, Eurydice, \& Eurostat, 2014, p. 82) providing information on the direct public expenditure per child in public preschool International Standard Classification of Education (ISCED) level 0 in 2010, we obtain a rather similar estimate of the cost per child $(\$ 4,107 ; € 3,614 ; € 5,130$ in 2010 prices).

The estimated costs of $\$ 4,027$ per child is substantially below the costs of some influential targeted model programs (i.e., around $\$ 14,500$ per child for Perry Preschool and around \$33,000 for the Abecedarian project; $\$ 17,526$ and $\$ 39,672$, respectively, in 2005-2006 prices; see Bartik et al., 2012, p. 1147). However, according to recent data on spending on U.S. state preschools (Barnett et al., 2016), the estimated costs per child in the Spanish program appear to be higher than the average costs of U.S. state preschools (around \$3,400 in 1997 prices; $\$ 5,123$ in 2015 prices). Interestingly, the costs of the Spanish program are in between the first two universal U.S. state preschool programs: the Georgia program (around $\$ 2,600 ; \$ 3,880$ in 2015 prices) and the Oklahoma program (around $\$ 5,200 ; \$ 7,782$ in 2015 prices). We therefore conclude that, while substantial variation between states in preschool costs exists, the costs of the Spanish program are in line with preschool costs documented for U.S. universal programs.

Finally, we should take into account an important caveat when using this estimate of the costs for one additional 3-year-old child in preschool. Theoretically, the expansion of public preschool may have crowded out private preschool and child-care arrangements (see Cascio \& Schanzenbach, 2013 for the United States and Blanden, Del Bono, McNally, \& Rabe, 2016 for the United Kingdom). However, Nollenberger and Rodríguez-Planas (2015) and Felfe et al. (2015, pp. 409-410) show that the reform did not significantly affect private preschool coverage of 3-year-olds: "our findings should be interpreted as the effects of an expansion in high-quality public child care, which mainly led to a crowding out of family care, but not to a crowding out of private or informal care arrangements" (Felfe et al., 2015, p. 409). This is crucial for our cost-benefit analysis because if the expansion of public preschool had crowded out private preschool, the additional societal costs would be lower. In fact, in the case of a perfect substitution, the reform would simply redistribute costs from parents to taxpayers rather than increase overall societal costs. In the case of the 
LOGSE reform, however, the additional costs (and benefits) arise because a larger number of children are enrolled in preschool.

\section{Benefits for Children}

Higher Lifetime Earnings Due to Improved Reading Skills

Felfe et al. (2015) document that the Spanish preschool expansion significantly increased age 15 PISA reading scores, but had no effect on their math test scores. Given that higher test scores reflect a higher level of accumulated cognitive skills, following a human capital model, the central assumption is that these gains will result in higher lifetime earnings (directly or indirectly through higher educational attainment). How to convert these higher test scores into monetary benefits over the entire life course is one of the crucial steps in our cost-benefit analysis.

Several studies, almost all based on U.S. data, have estimated the relation between test scores measured in childhood and adolescence and adult earnings (Carneiro, Crawford, \& Goodman, 2007; Chetty, Friedman, \& Rockoff, 2014; Lin, Lutter, \& Ruhm, 2016; Mulligan, 1999; Murnane, Willett, Duhaldeborde, \& Tyler, 2000). As this type of longitudinal evidence is not available for Spain, we rely on evidence from the United States. The reported relations depend not only on which skills are measured (e.g., numeracy, literacy, or a more general skills test) and when skills are measured (early childhood to late adolescence), but also the exact nature of the earnings measure (e.g., wages conditional on employment, annual earnings). Studies that focus on wage effects (conditional on being employed) of skills do not take into account the positive effect of skills on employment. Moreover, the estimated returns to skills depend on the age at which the earnings are measured (most studies focus on early career earnings). As evidence indicates that returns to skills increase over the life cycle (Hanushek, Schwerdt, Wiederhold, \& Woessmann, 2015; Lin et al., 2016), the results based on early career earnings may therefore substantially underestimate the relevance of skills for lifetime earnings (e.g., Böhlmark \& Lindquist, 2006; Haider \& Solon, 2006). These issues are important in our cost-benefit analysis as (changes in) lifetime earnings determine the preschool benefits.

In our main analysis, we base our parameter on recent estimates from the National Longitudinal Survey of Youth 1979 (NLSY79). Lin et al. (2016) show for the United States that the Armed Forces Qualification Test (AFQT) score (a composite cognitive test score) measured between ages 16 and 23 predicts earnings several decades later, with stronger effects on earnings later in life. Conditional on background characteristics and noncognitive skills, a $1 S D$ increase in cognitive skills increases annual labor earnings by $17 \%$ (by age 28 ), $24 \%$ (by age 38 ), and $26 \%$ (by age 48 ). The effect on hourly wages is somewhat weaker: between $13 \%$ and $18 \%$ for the different age groups. It appears that the hourly wage results are close to the U.K. estimates: $1 S D$ higher cognitive test score (measured at age 11) is associated with a $19.4 \%$ higher hourly wage at age 42 (compared to $18 \%$ by age 48 for the United States; Carneiro et al., 2007, p. 36). Around $70 \%$ of the effect of skills on annual earnings appears to be driven by hourly wages; the remainder of the effect is due to differences in annual hours of work (i.e., the employment effect). Interestingly, Lin et al. (2016) estimate that total lifetime labor income (through age 65, using a 3\% discount rate) increases by $21.5 \%$ per $S D$ increase in AFQT score.

Because we aim to convert the gains in PISA reading scores by Spanish children into increased lifetime earnings, we should take into account that the U.S. result is based on general skill measures. Lin et al. (2016) use the AFQT score, which is based on four cognitive skill tests (math knowledge, arithmetic reasoning, word knowledge, and paragraph comprehension). It is plausible that more general cognitive skill measures are better predictors of earnings than a score in a single cognitive domain (i.e., literacy in our case). Moreover, returns to skills are different from one country to another: institutional factors, the country's wage structure (i.e., the extent to which wages are compressed), and labor market conditions determine returns to skills. To correct for the difference in returns to skills between the United States and Spain as well as the finding that the Spanish preschool reform affected reading but not math skills, we use the comparative evidence provided by Hanushek et al. (2015; see Appendix S3 for details). Using cross-sectional Programme for the International Assessment of Adult Competencies (PIAAC) data for 23 countries, including Spain and the United States, Hanushek et al. (2015) estimate the relations between wages and numeracy as well as literacy skills. These results suggest that returns to skills in Spain are about $81 \%$ of the returns in the United States. In addition, we estimate that around $43 \%$ of the returns to overall (numeracy and literacy) skills can be attributed to literacy skills. 
To calculate our final returns to literacy skills parameter for Spain, we use the correction factors discussed earlier $(0.17 \times 0.8145 \times 0.4339)$, which results in a parameter score of 0.06 . We use this single parameter for all ages. This may be plausible as, based on cross-sectional evidence, returns to skills do not appear to increase significantly with age in Spain (Hanushek et al., 2015, p. 112). In our sensitivity analysis, we show how the results are affected if alternative (plausible) values of the returns to skills parameter are used.

To estimate children's benefits due to improved literacy skills, we multiply the TOT effect (about $0.6)$ by the returns to skills parameter (0.06) and the base cumulative discounted lifetime earnings (Appendix S3). For our base scenario, we assume that the relevant cohort has the potential to be active on the labor market between ages 16 and 70; the relevant years are 2010 (when the cohort is 16) until 2064 (when the cohort is 70). We calculate the annual earnings by multiplying (estimated) average wages of workers by age and the (estimated) employment rate by age.

For average wages of workers, we use the Structure of Earnings Survey (Eurostat, 2002, 2006, 2010, 2014). This worker survey provides data every 4 years from 2002 until 2014 and contains average annual earnings by 10 -year age group. Comparing this wage data with wage data provided by OECD (2016a, 2016b), it appears that the average annual wage according to the Structure of Earnings Survey is somewhat below the average annual wage reported by OECD (e.g., €25,766 vs. €27,408 in 2014). Although these OECD statistics do not provide age-specific wage data (the average wage is on national accounts data), this suggests that we use a conservative base wage.

To estimate age-specific annual wages, we use a linear transformation of the average wage per age group, taking the average to be reached exactly in the midpoint of the age category. Missing wage data between 2010 and 2014 are interpolated by assuming smooth wage growth between known data points; wage data beyond 2014 is extrapolated using a $0.8 \%$ wage growth rate per year in real wages, which is the average real wage growth for Spain in the period 1990-2015 (OECD, 2016a).

Since not all children will be continuously employed throughout their life, we correct for agespecific employment rates using data from the Spanish Labour Force Survey (LFS). As the LFS provides employment rates for 5-year age groups, we estimate age-specific employment rates, again applying a linear transformation. Furthermore, we use European Union projections on future employment rates (European Commission, 2015, p. 322) to take into account expected changes in the employment rate. Country-specific projections for employment rates (ages 20-64) in 5-year intervals are provided, and we interpolate missing data assuming that the employment rate increases linearly from 2015 (our last data point) until 2020, from 2020 to 2025, and so on. Next, for the years 20162064, we calculate a correction factor by dividing the projected average employment rate by the actual average employment rate (ages 20-64) in 2015. By multiplying the age-specific employment rate by this correction factor, we calculate the final age-specific employment profiles.

\section{Earlier Labor Market Entry Due to Reduced Grade Retention}

Felfe et al. (2015) demonstrate that the Spanish preschool expansion for 3-year-olds reduced grade retention in primary school, probably because ECEC participation increases school readiness of young children. This result implies that, ceteris paribus, affected children are able to graduate and enter the labor market at a younger age. We estimate the benefits for children of reduced grade retention by multiplying the base wage (as described earlier) at age 21 (the average age of finishing education in Spain in 2009 OECD, 2011) with this age group's employment rate of individuals not in education. We use the employment rate of individuals not in education instead of the (lower) overall employment rate as we aim to calculate the benefits of completing education (i.e., not being in education anymore) earlier versus later.

In addition to the earlier labor market entry effect, one may argue that reduced grade retention also affects earnings later in life (e.g., Bartik, Gormley, Belford, \& Anderson, 2016). However, we argue that this effect operates through skills and since we already include lifetime earnings effects through improved (literacy) skills in our analysis, we would double count the benefits if we included such additional earnings effects.

\section{Benefits for Parents}

\section{Short-Term Employment Effect}

The Spanish reform encouraged the employment of mothers, thus generating a short-term employment effect: On average, maternal employment 
increases by nearly 0.2 for every additional 3 -yearold in preschool (Table 1).

We derive the base scenario for mothers using the same data sources and interpolation strategies as for our base scenario for children, except that we use female instead of total (male plus female) annual earnings and employment rates. Estimating the monetary benefits of this short-term employment effect is rather straightforward: To calculate the benefits per child, we multiply this employment effect parameter by the base earnings in the year 1997 of women aged 32 (i.e., the average age of mothers of a 3-year-old; Nollenberger \& RodríguezPlanas, 2015).

\section{Long-Term Earnings Gains Due to Earlier Labor Market (Re-)Entry}

A second, indirect effect of the ECEC expansion is that it decreases the length of mothers' career interruptions, and thereby positively affects their human capital stock and basically reduces the motherhood penalty. It may not be surprising that larger motherhood penalties are found in countries that provide relatively limited support to working mothers (Gash, 2009). Given that there is no direct evidence available on how ECEC policies reduce the motherhood penalty, we base our estimate of the longer run wage effect of ECEC on three streams of literature: (a) career interruptions (e.g., Felfe, 2012; Kunze, 2002; Mincer \& Ofek, 1982; Spivey, 2005), (b) parental leave (e.g., Schönberg \& Ludsteck, 2014), and (c) returns to labor market experience after childbirth (Ejrnæs \& Kunze, 2013): see Appendix S4 for a more extensive discussion.

Our conclusion from these three strands of literature is that career interruptions decrease wages and that this effect diminishes with time since re-entry. We take the results of Spivey (2005) as our frame of reference for three reasons: Spivey explicitly models the dynamics of wage losses after a career interruption, the results are consistent with the idea of large but diminishing negative effects, and the estimates are within the range of most other studies. As not all the coefficients of the career interruption penalty are significant 5-9 years after the interruption, we use the average effect of these 5 years (considering insignificant effects to be 0 ) for the parameters to calculate the effect on postentry wages. Accordingly, wage differences (in percentage) between treatment and control in the 9 years after re-entering the labor market are 7.6, 4.6, 2.9, 2.0, and 1.6 for the last 5 years. To calculate the relevant benefits, we multiply the number of additional mothers in employment ( 0.18 per child in preschool) with the change in the base wages for the relevant ages (33-41, years 1998-2006) and account for future career interruptions by correcting for the relevant age and gender-specific employment rates.

\section{Benefits for Taxpayers}

Taxpayers gain as the lifetime earnings of mothers and children increase. We use tax rates on gross labor income provided by the OECD (2016b) to calculate the benefits for taxpayers. We do not consider social security contributions as benefits for taxpayers, as these are related to entitlements (unemployment benefits and pensions) of parents and children.

In addition to increased taxes, which are derived benefits that affect the distribution of benefits but not the size of the total societal benefits, taxpayers also benefit from the reduction in primary school grade retention. In the Spanish educational system, the large majority of children attend free public schools (i.e., fully publicly funded): the reduction in primary school grade retention therefore implies a benefit for taxpayers. Children spend 6 years in primary school (ages 6-12) if they do not retain a grade. This implies that the children aged 3 in 1997 who are not retained due to the reform finished primary school in 2005 instead of 2006. To calculate the grade retention benefits for taxpayers, we multiply the discounted costs per child in preschool and primary school per child by the estimated TOT effect of not retaining a grade. In this calculation, we use our estimate of the costs per child in preschool and primary education (see earlier for a more extensive discussion): $€ 4,633$ for the seventh year of primary school in 2006 (€4,762 in 2007 prices) implies a discounted value of $€ 3,551$ $(\$ 4,035)$.

\section{Results \\ Base Results}

The main results are presented in Table 2. The net benefits of the preschool investments for society in present value are substantial: over $\$ 13,000$ per 3year-old child in preschool, implying a benefit-cost ratio of about 4.3. In other words, for every dollar invested in ECEC, society gets back more than $\$ 4$. To illustrate the total economic benefits of extending preschool eligibility to 3-year-olds, we aggregate the societal costs and benefits of one entire cohort. In the academic year 1997-1998, 154,063 
Table 2

Costs and Benefits of Universal Early Childhood Education and Care

\begin{tabular}{lcccc}
\hline & For children & For parents & For taxpayers & For society \\
\hline Measured effects & & & & \\
$\quad$ Grade retention effect on costs primary school & - & - & 375.34 & $375.34(203.31)$ \\
$\quad$ Maternal employment & - & $2,785.18$ & 475.24 & $3,260.42(1,863.10)$ \\
Projected effects & & & \\
$\quad$ Grade retention effect on labor market entry & 376.88 & - & 64.31 & $441.19(238.98)$ \\
$\quad$ Improved skills effect on lifetime earnings & $10,893.00$ & - & $1,858.69$ & $12,751.69(5,547.81)$ \\
$\quad$ Reduction wage penalty for mothers & - & $3,210.41$ & 22.57 & $447.88(255.93)$ \\
Total benefits & $11,269.88$ & & $2,796.15$ & $17,276.52$ \\
Total costs & & $-4,027.79$ & $-4,027.79$ \\
Net present value & $11,269.88$ & $3,210.49$ & $-1,231.64$ & $13,248.73$ \\
Benefit-cost ratio & & & 0.69 & 4.29 \\
\hline
\end{tabular}

Note. Costs and benefits are presented in 1997 dollars; present values are calculated using a discount rate of 3\%. Monetized standard errors in parentheses. These standard errors are calculated using the standard errors of the difference-in-differences estimations (Table 1).

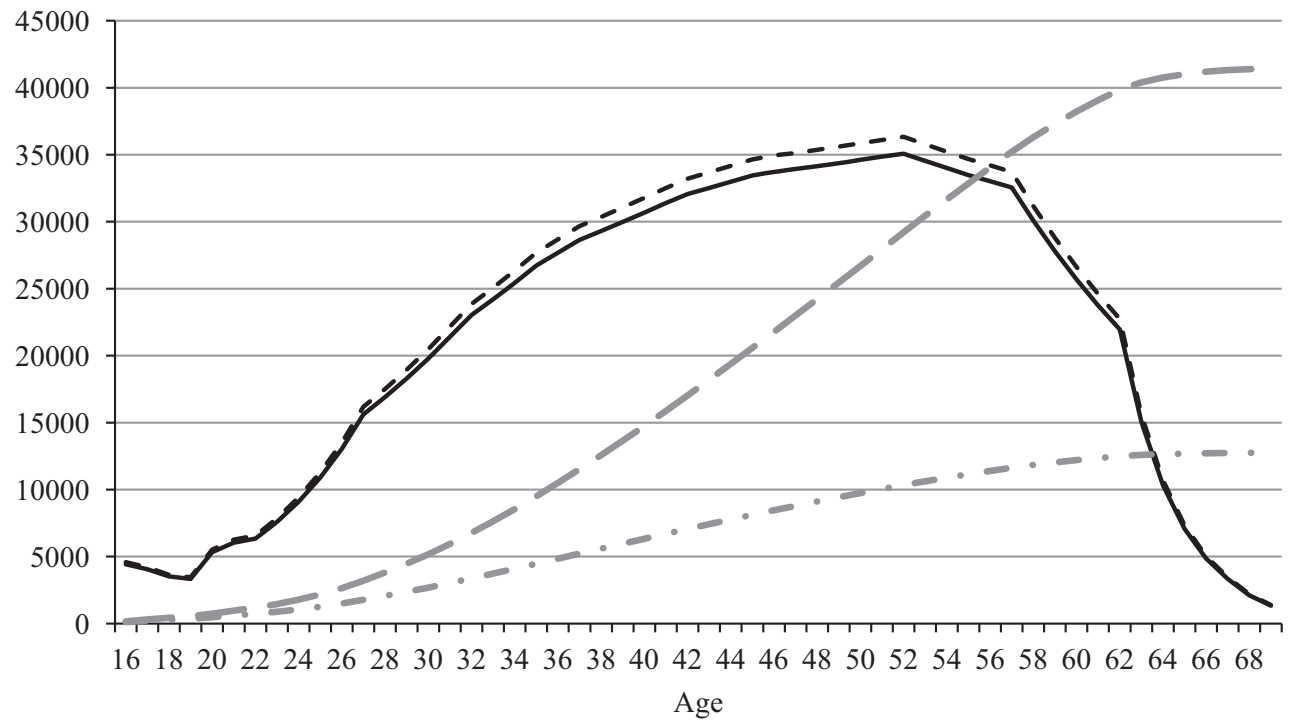

$\longrightarrow$ Control - - - Treatment $\longrightarrow$ Cumulative Gains $-\cdots$ Cumulative Gains (Discounted)

Figure 1. Estimated future earnings profiles of children (control vs. treatment).

Note. Treatment-on-the-treated effects are used to calculate the gross earnings profiles of the treatment group. A $3 \%$ discount rate is used to calculate the cumulative discounted gains in lifetime earnings: At age 70, the cumulative discounted gains in gross lifetime earnings are estimated at 12,751.69 (see Table 2).

three-year-old children were enrolled in public preschool. The total estimated costs of ECEC for these children are $\$ 620$ million, but according to our baseline results this investment generated a $\$ 2.66$ billion societal benefit in (1997) discounted value (i.e., $\$ 2.04$ billion net benefits). The net benefits of the investment account for $0.35 \%$ of GDP.

In addition to the size of the total benefits, the analysis provides insights into the distribution of the benefits. It is clear that children are the main beneficiaries of the ECEC expansion: about $65 \%$ of the total benefits accrue to children, while parents and taxpayers both receive $<20 \%$ of the benefits. The result that mainly children benefit from ECEC is due to the fact that they are able to profit from improved cognitive skill levels during their entire working life. This is illustrated in Figure 1, which shows the estimated lifetime gross earnings profiles of children enrolled in preschool at age 3 (treatment) and those not enrolled (control) as well as 
the cumulative benefits of treatment over the lifetime. The figure indicates that the largest (nondiscounted) earnings benefits are realized around the late $40 \mathrm{~s}$ and early $50 \mathrm{~s}$, as base earnings are the highest during this phase in the life cycle. At age 70 , the cumulative earnings difference between the control and treatment group is $3.6 \%$ (representing over $\$ 41,400$ in undiscounted terms).

To indicate the relative importance of the benefits for children and parents, we calculated the benefit-cost ratio in the case that there would be either no effect on child development or no effect on maternal employment. On the one hand, if there were no significant benefits for children, the benefit-cost ratio drops below 1 (to 0.92), implying that the ECEC investment results in a societal loss. In this case, costs should drop by almost $80 \%$ to an implausible value of $\$ 865$ per child to obtain the same benefit-cost ratio as in our base result. On the other hand, if there were no significant gains in terms of maternal employment, the benefit-cost ratio declines to 3.4 (and costs should decrease to around $\$ 3,160$ to maintain the original benefit-cost ratio), indicating that there would still be substantial net societal benefits.

Although children's benefits consist of two components, most of these benefits are due to improvements in literacy skills. A partial CBA, taking only into account the lifetime earnings benefits due to literacy skills gains, indicates a benefit-cost ratio of around 3.2. In fact, a TOT effect on literacy scores of about one third (0.19 instead of 0.6$)$ is sufficient to generate a ratio of earnings benefits to costs $>1$.

Finally, it should be noted that the distribution (but not the size) of the benefits depends crucially on the tax rate. In our base results, taxpayers receive around 70 cents back for every dollar invested in universal ECEC, implying a negative impact on the government budget balance. However, this result is highly sensitive to the estimated tax rate and whether or not social security contributions are included. For example, taxpayers receive more than $\$ 1$ back for every dollar invested when using the tax rate estimated by Nollenberger and Rodríguez-Planas (2015).

In addition to the level of the benefits, Table 2 includes the monetized standard errors of the estimated reform effects (reported in Table 1). This provides an indication of the uncertainty associated with the point estimates of the benefits. While the standard errors associated with the maternal employment benefits are relatively large (compared to the size of the benefits), in absolute terms the standard error with respect to the children's skills effect is the largest. This shows that the uncertainty around children's benefits drives the uncertainty of the overall results of the CBA.

To further assess this issue, we performed several simulations to assess the uncertainty associated with the point estimate of the benefit-cost ratio: the results are presented in Figure 2. These simulations are based on 1 million iterations and take into account the standard errors associated with the point estimates of all separate benefits. In the main simulations, the other parameters (base earnings, returns to skills parameter, costs) are assumed to be fixed and therefore do not incorporate, for instance, the prediction error surrounding the base earnings. These simulation results indicate that in $98.7 \%$ of the iterations the benefits outweigh the costs. Moreover, within the 5th and 95th percentile, the benefit-cost ratio varies between 1.86 and 6.72. When we allow for uncertainty in the projection of the children's benefits by using a standard error of 0.01 (as reported in Lin et al. 2016) for the 0.17 returns to skills parameter, the uncertainty around the benefit-cost ratio is only marginally affected: in these simulations, the benefit-cost ratio varies between 1.85 and 6.76 within the 5th and 95th percentile. As can be seen in Figure 2, when we allow for more uncertainty (a standard error of 0.04 instead of 0.01 for the returns to skills parameter), there is a clear but minor shift in the distribution of ratios: $98.6 \%$ of the iterations indicate positive net returns and the benefit-cost ratio varies between 1.74 and 7.25 within the 5th and 95th percentile. Overall, the simulations indicate that there is considerable uncertainty around the point estimate of the returns to

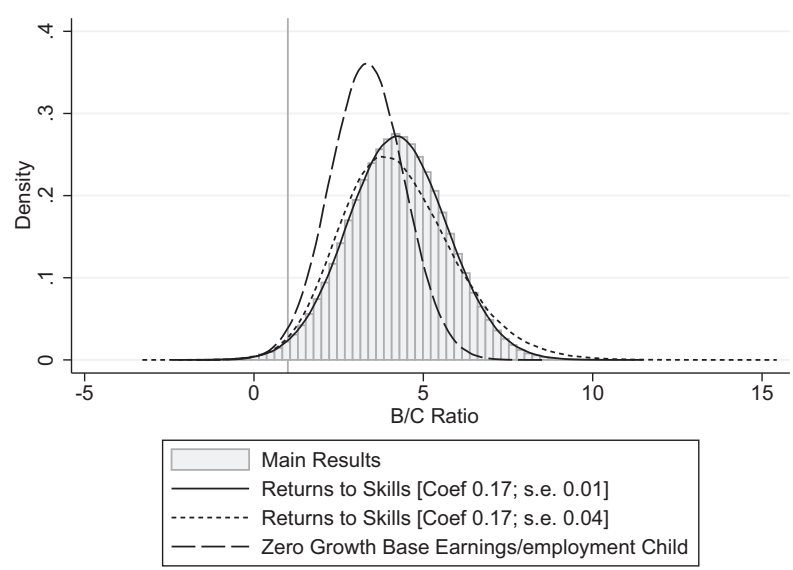

Figure 2. Simulation results (benefit-cost ratios).

Note. The simulation results of the base model are shown in the histogram; the simulations results of the other models are presented by kernel density plots. 


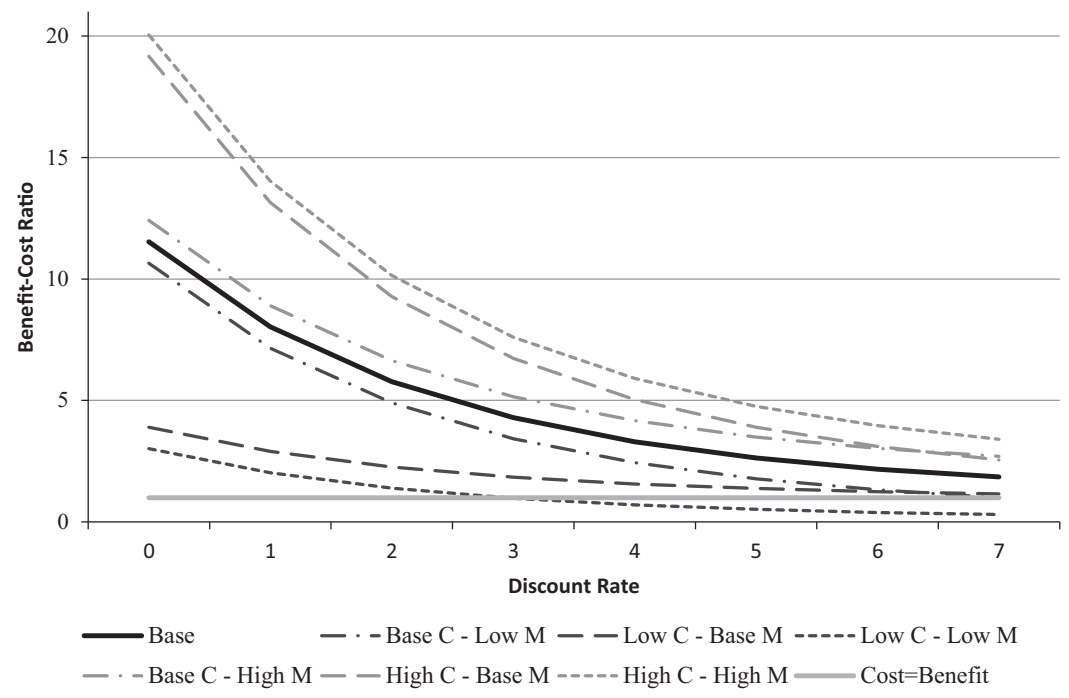

Figure 3. Scenarios-confidence intervals.

the preschool investment, but that it is highly likely that the societal benefits outweigh the costs.

\section{Sensitivity Analysis}

\section{Discount Rate}

Given that children's lifetime earnings benefits constitute the largest part of the total benefits and that these benefits materialize in the longer run, it can be expected that the discount rate matters. We estimate the cost-benefit ratio using discount rates within the range of $0 \%-7 \%$ (as in, e.g., Reynolds et al., 2011): see Figure 3 and Table E1 in Appendix S5. For these values of the discount rate, the benefit-cost ratio according to the base scenario varies between 11.53 and 1.85. Hence, the level of the benefits is highly dependent on the discount rate, but even for a discount rate of $6 \%-7 \%$, the benefits are about twice as large as the costs.

\section{Confidence Intervals of Effect Sizes}

Because our cost-benefit analysis is based on the estimated causal effects on maternal employment and child development, we vary the effect sizes using the lower and upper bound of the $90 \%$ confidence intervals (see Table 1). We calculate the benefit-cost ratios under six alternative scenarios:

1. Base C-Low M: lower bound maternal employment effect; base effects for child development;

2. Low C-Base M: lower bound child development effect; base effects for maternal employment;
3. Low C-Low M: lower bound maternal employment and child development effect;

4. Base C-High M: upper bound maternal employment effect; base effects for child development;

5. High C-Base M: upper bound child development effect; base effects for maternal employment;

6. High $\mathrm{C}-$ High $\mathrm{M}$ : upper bound maternal employment and child development effect.

The benefit-cost ratios of these six different scenarios using discount rates within the range of $0 \%-$ $7 \%$ are presented in Figure 3 (see also Table E1 in Appendix S5). The figure indicates two striking results. First, the benefit-cost ratio is above 1 in all scenarios and for all discount rates within the $0 \%-7 \%$ rage, except for the "Low C-Low $\mathrm{M}^{\text {" scenario when }}$ a discount rate of 3 or higher is used; in that case the ratio is just below 1 . Hence, under most scenarios the analysis indicates that the ECEC investment generated positive net benefits to society. According to these scenarios, a benefit-cost ratio of 7.6 represents the upper bound ("High C-High M").

Second, consistent with our base results (and the standard errors reported in Table 2), the benefitcost ratio appears to be highly sensitive to the benefits for children but rather insensitive to variation in the estimated maternal employment effect. Interestingly, the confidence interval around the maternal employment effect varies from almost no (economically significant) effect to a quantitatively large effect (the upper bound [0.35] is close to the largest effects found in the quasi-experimental literature, e.g., Bauernschuster \& Schlotter, 2015). In other 


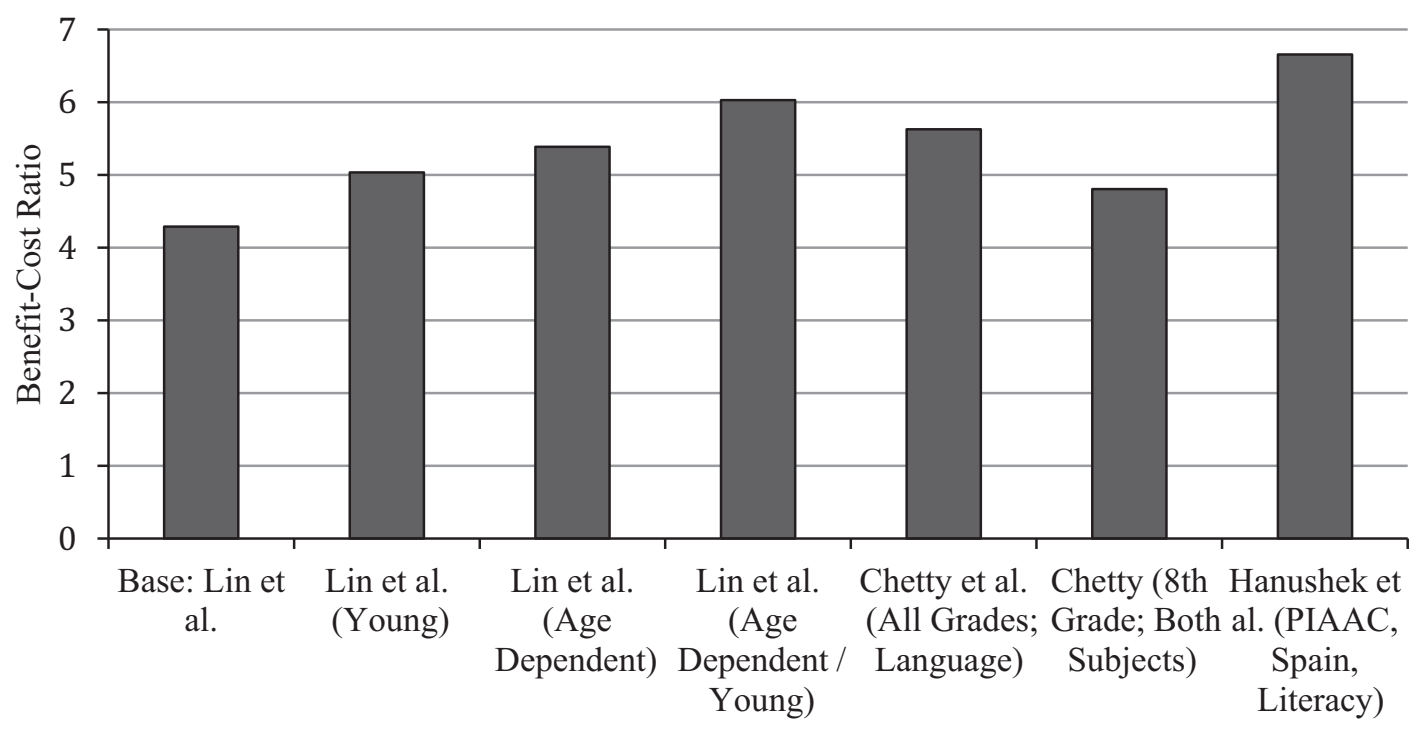

Figure 4. Benefit-cost ratios using alternative return to skills parameters.

words, even though the scenarios ("Base C-Low $\mathrm{M}^{\prime \prime}$ and "Base C-High $\mathrm{M}^{\prime \prime}$ ) cover basically the entire literature on causal effects of universal ECEC on maternal employment, the difference in cost-effectiveness is rather small.

\section{Returns to Skills Parameter}

The earnings benefits for children and therefore the total benefits are dependent on the value of the returns to skills parameter (see Appendix S3). We examined whether our main results are robust to using alternative parameters: Figure 4 shows the estimated benefit-cost ratios for this sensitivity test.

First, we use three alternative approaches based on Lin et al. (2016). For our base results, we use a parameter that captures the relation between skills measured at ages 16-23 and annual earnings at age 28. However, Lin et al. (2016) report higher returns when earnings are measured later in life: from $17 \%$ by age 28 (our base parameter) to $24 \%$ by age 38 and $26 \%$ by age 48 (when skills are measured at ages $16-23)$. We estimated the benefit-cost ratio based on these three estimates, using $17 \%$ for ages below 28 and 26 for ages above 48 and a linear transformation between the three age points. Next, Lin et al. (2016, p. 61) show that returns are higher when test scores are measured at a younger age (ages 16-18): in that case the estimate of the returns to skills is $21 \%$ instead of $17 \%$. As in our study skills are measured at age 15, using this higher value is plausible. Finally, Lin et al. (2016) also provide evidence of increasing returns over the life cycle when test scores are measured at a younger age (the estimates are 21, 23, and 32 for the ages 28 , 38 , and 48 , respectively). Based on these three alternative approaches, the benefit-cost ratio increases to 5-6.

Second, instead of using the estimates provided by Lin et al. (2016), we used the returns to skills estimates reported by Chetty et al. (2014). The partial CBA by Cascio and Schanzenbach (2013) is also based on the parameters provided by this study. Chetty et al. (2014) document the relation (again for the United States) between math and language (English) test scores measured in grades 4-8 (ages 9-13) and age 28 earnings, based on administrative data consisting of 1.3 million observations. Based on their results, we use two alternative parameters: one is based on the relation between Grades 4 and 8 language test scores and adult earnings; the other is based on the relation between Grade 8 (i.e., in terms of age relatively close to our sample) scores on both math and language test scores (see Appendix S5, E2 for details). Using these two alternative parameters, the estimates of the benefit-cost ratios are 5.6 and 4.8 , respectively.

Finally, we used the results reported by Hanushek et al. (2015, p. 125). An important limitation of using these results is that they are based on cross-sectional data, providing evidence on current (instead of adolescent) skills and current earnings. However, an advantage is that this estimate is based on recent (PIAAC) data for Spain and that estimates for literacy skills (conditional on numeracy skills) are provided. Using this estimate $(10.5 \%)$, the benefitcost ratio is 6.65 . 
The results based on alternative returns to skills parameters point out that our base results are somewhat conservative, as we assume a relatively low (conservative) returns to skills parameter.

\section{Base Lifetime Earnings}

In our base model, we use a linear transformation of wages (which is available for 10-year age groups) and of employment (which is available for 5-year age groups) to estimate children's lifetime earnings base profile. To test to what extent this strategy drives our results, we generated base scenarios (a) without a linear transformation of wages (i.e., assuming the same average wage within each age group), (b) without a linear transformation of employment (i.e., assuming the same employment level within each age group), and (c) without a linear transformation of wages and employment. These alternative approaches produce slightly higher base profiles and benefit-cost ratios (between 4.35 and 4.45; see Table E3 in Appendix S5). Our main results therefore do not seem to be affected critically by our interpolation/extrapolation strategy for the base earnings.

In addition to the linear transformation of wages and employment levels, for our base results we assume a real wage growth of $0.8 \%$ and use future employment projections to estimate growth in employment rates. Assumptions on these growth rates are likely to matter considerably for the base profile. We therefore estimated base lifetime earnings and the benefit-cost ratio assuming (a) zero wage growth, (b) zero employment growth, and (c) zero wage and employment growth. While the alternative estimates show that base earnings are significantly lower under the zero growth scenarios, benefits outweigh costs by more than a factor 3 even in pessimistic scenarios about future wage and employment developments (Table E3 in Appendix S5; see also Figure 2 for the simulation results using the third alternative base profile).

\section{Alternative Estimation Approach}

For our base results we calculate the benefits for children by multiplying the TOT effect on literacy skills by a returns to literacy skills parameter and the children's base earnings profile. Alternatively, we could separately estimate the effect on wages, conditional on being employed (intensive margin), and on employment (extensive margin). In that case, we need to apply two returns to skills parameters (i.e., one with respect to wages and one with respect to employment). The results, as well as a more elaborate discussion of this approach, can be found in Appendix S5, E4. Interestingly, this alternative estimation strategy leads to very similar results (the benefit-cost ratio of 4.5 instead of 4.3).

\section{Heterogeneous Child Development Effects}

Our main analysis uses estimated child development effects that are based on the pooled sample of children to extrapolate the benefits for children. Existing literature indicates that children of lower socioeconomic status (SES) parents benefit most (or only) from ECEC (Elango et al., 2015; Melhuish et al., 2015; Van Huizen \& Plantenga, 2015). Consistent with the existing literature, Felfe et al. (2015) show that the effect on PISA reading scores is statistically significant in the sample of children of whom neither parent has a secondary school degree, and is not significant in the sample of children from families in which at least one parent has a secondary school degree. Accounting for these heterogeneous effects is important in our analysis, as on the one hand larger benefits can be expected due to the larger effect size for the low SES group (ITT of 0.168 instead of 0.154 ), but on the other hand benefits will be smaller as the gains are calculated among a much smaller number of children (the low SES group represents about one fourth of the total sample).

We recalculate the benefits of the ECEC expansion using the relevant, larger effect size and correcting for the lower share of children benefiting from the investment. In our calculation of the TOT, we assume that the expansion increased coverage rates equally among the different SES groups. We would underestimate the effect if the reform increased the use of ECEC services less among lower SES families than among higher SES families (and vice versa). Furthermore, we use the same base earnings scenario as in our main results. Since lower SES groups have below average wages and employment rates, the benefits will actually be smaller. Hence, we should interpret these findings cautiously. The results (Table E5 in Appendix S5) show that if only lower SES children benefit from the ECEC expansion, the societal benefits decline by more than $50 \%$. However, the benefit-cost ratio is still substantially above 1 .

\section{Discussion}

Universal ECEC programs have been implemented in various European countries and U.S. states and 
cities. In general, these programs aim to promote child development as well as maternal employment. Although universal ECEC programs involve a substantial amount of public spending, little evidence exists on the cost-effectiveness of these investments. This study examined to what extent investments in universal preschool payoff in the long run, focusing on the Spanish LOGSE reform. This reform reduced the age of eligibility for universal publicly provided preschool from age 4 to age 3 and led to a strong increase in the enrollment rate of 3-year-olds in these arrangements. Moreover, quality standards were raised. In a matter of a decade, preschool enrollment among 3-year-olds increased from low to nearly universal: by now, millions of children have participated in the program.

Evidence based on a DD approach shows that the expansion of the new, higher quality preschool services improved child development and had a positive impact on maternal employment. We estimated the societal benefits on the basis of these estimated causal effects, taking into account these benefits for both parents and children. Our base results indicate that the benefit-cost ratio is over 4 . Sensitivity tests suggest that our base estimate is somewhat conservative and that it is likely that the investment generates a positive net present value for society. Furthermore, our cost-benefit analysis shows that the gains for children are the main driver of the total societal gains of universal ECEC. The maternal employment effects are quantitatively nontrivial but play a relatively modest role.

\section{A Comparative Perspective}

This study represents one of the first causal evidence-based CBAs of universal preschool programs. To compare our findings with existing evidence on the cost-effectiveness of preschool programs, Table 3 provides an overview of recent CBA studies. In addition to the overall benefit-cost ratio, the table indicates the ratio of the children's lifetime earnings gains over the costs. The latter ratio is not only relevant because it refers to the principal benefit in our analysis, but it also provides a useful score for comparative analysis as it can be calculated for all reported CBA studies.

The first striking result is that all the estimated benefit-cost ratios are above 1 , indicating a net positive return for society. In fact, almost all estimates indicate that society receives back at least $\$ 2.5$ for every dollar invested. There appear to be two exceptions. However, the early ABC assessment (Barnett \& Masse, 2007) seems to underestimate the benefits, given the more favorable results of the later $\mathrm{ABC}$ evaluation by García et al. (2016). The study by Bartik et al. (2016) probably also underestimates the benefits since the estimated benefits are driven only by those children who would have been retained in the absence of the preschool program; the child development gains of all other children are not included in their analysis.

Second, despite the difference in context, the findings from our study appear to be largely consistent with the other natural experiment CBAs of universal programs. Even more striking are the similarities with the evaluations of targeted interventions. While some of these programs score a far more impressive overall ratio (Heckman et al., 2010; Reynolds et al., 2011), if we focus solely on children's lifetime earnings gains, the cost-effectiveness of the Spanish preschool program appears to be somewhat lower than Perry, comparable to CPC and higher than $\mathrm{ABC}(/ \mathrm{CARE})$. This is a remarkable result, given the differences in methodology (RCT vs. natural experiment), the program features (content, intensity, duration), specific population, and context. Apparently, the returns of (some) targeted interventions are more impressive because of the inclusion of other benefit components (especially crime reduction).

\section{Limitations}

This study provides new insights into the costeffectiveness of universal preschool programs. However, we should consider the findings in light of the limitations of this study. First, evidence on the immediate and short-term child development effects of the program is not available and therefore the exact channels through which the long-term (age 15) benefits of the program are generated are not clear. Nevertheless, a large number of studies do provide such evidence for other programs, suggesting that high-quality programs have the potential to increase both cognitive and noncognitive skills.

Second, an important limitation is that most of the benefits are projected. This issue is especially relevant for the largest benefit component: children's lifetime earnings gains. While the exact point estimates of these benefits are rather uncertain, simulation results and sensitivity analyses indicate that it is likely that the benefits outweigh the costs. Furthermore, it should be noted that this limitation applies by definition to all CBAs of more recent programs as it takes time for benefits to materialize. An important limitation of CBAs on realized 


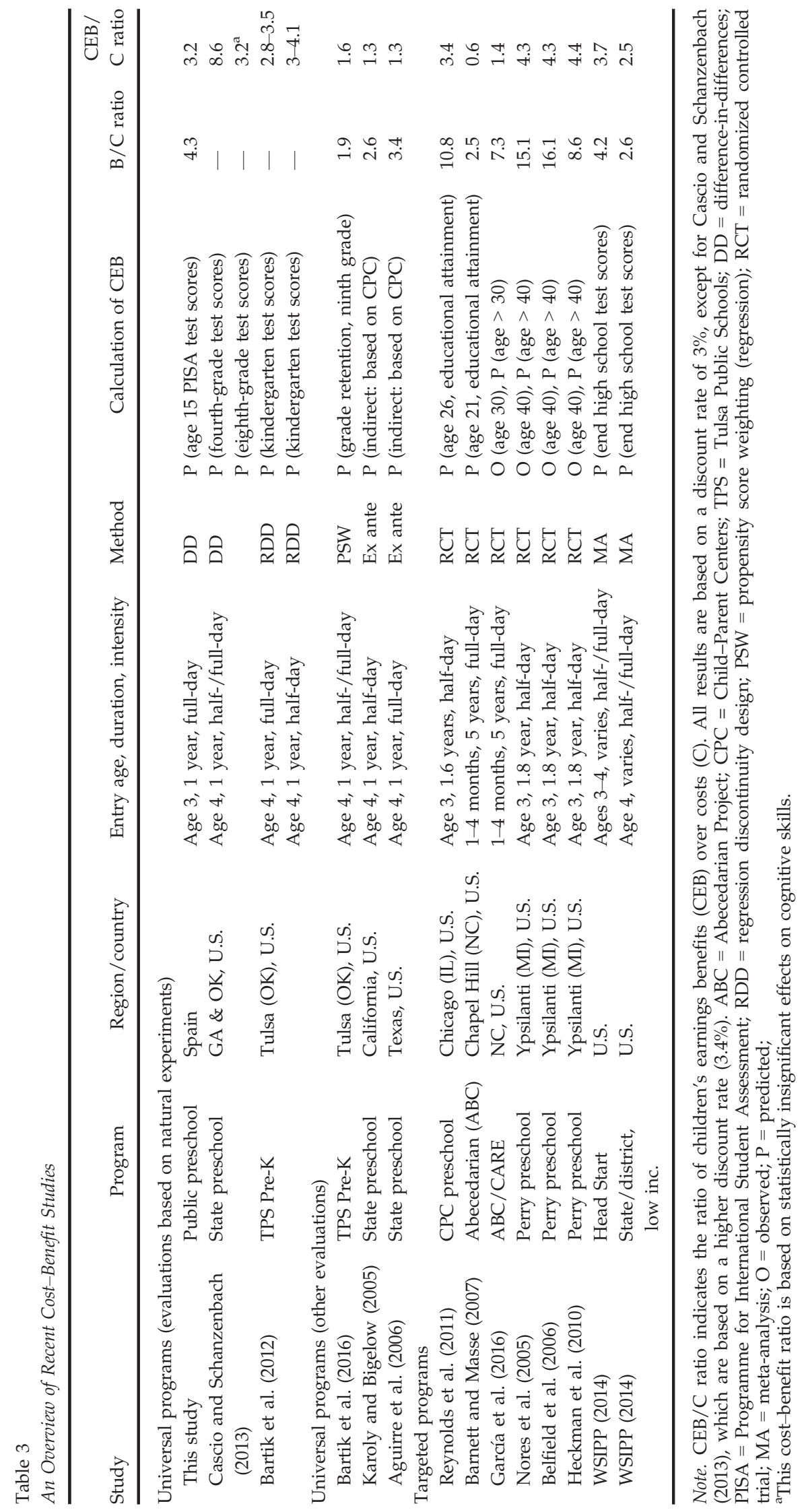


earnings benefits is that contexts may have changed considerably and that results may no longer be relevant for today's policy discussions.

A third limitation of our CBA is that we focus mainly on the benefits in terms of lifetime earnings of parents and children. We thereby exclude several other benefits that may be relevant. For instance, parents may benefit from preschool as it frees up time that may be used for other purposes than paid employment: leisure, education, informal labor (household production), community services, and so on. Moreover, there may be additional benefits for society (social inclusion) or for children. For example, unlike some studies on targeted interventions (e.g., Barnett \& Masse, 2007; Heckman et al., 2010; Reynolds et al., 2011), we do not include the benefits of reduced crime rates, improved health, and increased income of future generations. However, as the LOGSE reform affected the general population rather than disadvantaged children, the gains per child in terms of crime reduction, and health improvements may be rather limited in this case.

\section{Policy Implications}

The Spanish case provides some general lessons on the cost-effectiveness. Perhaps the most important policy conclusion is that the expansion of preschool programs for all 3-year-olds has the potential to generate substantial returns in the long run. However, the institutional context matters. When the LOGSE reform in Spain was implemented, there was a lack of supply of alternative center-based preschool or child-care facilities. As a result, the crowding out of alternative formal services was limited. This specific condition may no longer apply in many developed countries, as formal preschool or child-care facilities for 3- and 4year-olds have become increasingly available and implementing universal preschool may crowd out these services. In the United States, for instance, the introduction of a nationwide universal preschool program will crowd out state prekindergarten and Head Start programs. The effect sizes-and thereby the level of the benefits - may be smaller depending on the quality and intensity of the counterfactual. If a universal preschool will substitute for a highquality targeted program, benefits are likely to be small (if any). For the same reason, effect sizes of preschool programs are smaller in more recent studies (Duncan \& Magnuson, 2013). For example, effects found in the Head Start Impact Study are quite modest (the majority of the control group participated in another center-based facility). Of course, benefits may be lower, but so are the marginal societal costs. Given that the counterfactual formal ECEC arrangement is often (partially) publicly funded, crowding out of these arrangements implies that marginal costs are below average costs per child. In other words, not all of what is spent on universal preschool is new spending. However, when the costs of counterfactual mode of care would have been mainly borne by parents, introducing a free universal program will substantially affect the distribution of costs, shifting a part of the burden from parents to the government.

Previous literature (Melhuish et al., 2015; Van Huizen \& Plantenga, 2015) shows that high ECEC quality is an important precondition for improvement in (non)cognitive skills. Mediocre-level ECEC arrangements are likely to produce insignificant effects or may even be harmful to child development. Since our analysis indicates that the lion's share of the total societal benefits of ECEC investments are the result of child development gains, it is crucial to invest in quality in order to obtain positive net returns for society. Future research should further unveil which specific elements of preschool quality are crucial to achieve high levels of costeffectiveness.

The analysis of the Spanish case also illustrates that the net present value of ECEC investments not only depends critically on whether children (on average) benefit, but also on which children benefit (most) from ECEC. Consistent with most previous evidence from natural experiments (Elango et al., 2015; Van Huizen \& Plantenga, 2015), the main beneficiaries are children from lower educated parents. The limited use of (high-quality) ECEC services by lower SES families, whose children actually benefit most from participating in such services, is an issue that should be further addressed by public policy. Encouraging lower SES families to use high-quality ECEC services may be costly in the short-term, but may boost the benefit-cost ratio of ECEC investments considerably in the long run.

The relevance of quality and the general finding that low SES children benefit most from high-quality ECEC imply that providing universal preschool for free may not be optimal from a cost-benefit perspective. In general, there seems to be no strong case for fully subsidized preschool for high SES families, given that children from these families do not (significantly) benefit from participating in these services. Moreover, free universal preschool puts a substantial burden on government budget, which creates a risk: funding is likely to be more 
dependent on the economic and political climate. In fact, during the recent crisis years the Spanish government has made severe cuts in spending on preschool education. It is likely that these cuts have had negative effects on quality. Free high-quality preschool for lower SES families and an (incomedependent) fee for higher SES families ensure that high-quality preschool services are accessible and affordable for all.

\section{References}

Aguirre, E., Gleeson, T., McCutchen, A., Mendiola, L., Rich, K., Schroder, R., . . . Taylor, L. (2006). A cost-benefit analysis of universally accessible pre-kindergarten education in Texas. College Station, TX: Bush School of Government and Public Service, Texas A\&M University.

Angrist, J. D., \& Pischke, J.-S. (2008). Mostly harmless econometrics: An empiricist's companion. Princeton, NJ: Princeton University Press.

Attanasio, O., Low, H., \& Sanchez-Marcos, V. (2008). Explaining changes in female labor supply in a lifecycle model. American Economic Review, 98, 1517-1552. https://doi.org/10.1257/aer.98.4.1517

Baker, M., Gruber, J., \& Milligan, K. (2008). Universal child care, maternal labor supply, and family wellbeing. Journal of Political Economy, 116, 709-745. https:// doi.org/10.1086/591908

Barnett, W. S. (2011). Effectiveness of early educational intervention. Science, 333, 975-978. https://doi.org/10. 1126/science. 1204534

Barnett, W. S., \& Masse, L. N. (2007). Comparative benefitcost analysis of the Abecedarian program and its policy implications. Economics of Education Review, 26, 113-125. https://doi.org/10.1016/j.econedurev.2007.02.001

Barnett, W. S., Friedman-Krauss, A., Gomez, R., Horowitz, M., Weisenfeld, G. G., Brown, K. C., \& Squires, J. H. (2016). The state of preschool: 2015 state preschool yearbook. New Brunswick, NJ: National Institute for Early Education Research, Rutgers University.

Bartik, T. J., Gormley, W., \& Adelstein, S. (2012). Earnings benefits of Tulsa's Pre-K program for different income groups. Economics of Education Review, 31, 1143-1161. https://doi.org/10.1016/j.econedurev.2012.07.016

Bartik, T. J., Gormley, W., Belford, J. A., \& Anderson, S. (2016). A benefit-cost analysis of the Tulsa Universal Pre-K Program. Upjohn Institute Working Paper 16-261.

Bauernschuster, S., \& Schlotter, M. (2015). Public child care and mothers' labor supply-Evidence from two quasi-experiments. Journal of Public Economics, 123, 116. https://doi.org/10.1016/j.jpubeco.2014.12.013

Belfield, C. R., Nores, M., Barnett, S., \& Schweinhart, L. (2006). The High/Scope Perry Preschool Program costbenefit analysis using data from the age- 40 follow-up. Journal of Human Resources, 41, 162-190. https://doi. org/10.3368/jhr.XLI.1.162
Berlinski, S., Galiani, S., \& Gertler, P. (2009). The effect of pre-primary education on primary school performance. Journal of Public Economics, 93, 219-234. https://doi. org/10.1016/j.jpubeco.2008.09.002

Blanden, J., Del Bono, E., McNally, S., \& Rabe, B. (2016). Universal pre-school education: The case of public funding with private provision. Economic Journal, 126, 682-723. https://doi.org/10.1111/ecoj.12374

Böhlmark, A., \& Lindquist, M. J. (2006). Life-cycle variations in the association between current and lifetime income: Replication and extension for Sweden. Journal of Labor Economics, 24, 879-896. https://doi.org/10. 1086/506489

Carneiro, P., Crawford, C., \& Goodman, A. (2007). The impact of early cognitive and non-cognitive skills on later outcomes. CEE Discussion Paper No. 92.

Cascio, E. U. (2009). Maternal labor supply and the introduction of kindergartens into American public schools. Journal of Human Resources, 44, 140-170. https://doi. org $/ 10.3368 /$ ihr. 44.1 .140

Cascio, E. U., \& Schanzenbach, D. W. (2013). The impacts of expanding access to high-quality preschool education. Brookings Papers on Economic Activity, 127-178. https://doi.org/10.3386/w19735

Chetty, R., Friedman, J. N., \& Rockoff, J. E. (2014). Measuring the impacts of teachers II: Teacher value-added and student outcomes in adulthood. American Economic Review, 104, 2633-2679. https://doi.org/10.1257/aer. 104.9.2633

Cryer, D., Tietze, W., Burchinal, M., Leal, T., \& Palacios, J. (1999). Predicting process quality from structural quality in preschool programs: A cross-country comparison. Early Childhood Research Quarterly, 14, 339-361. https://doi.org/10.1016/s0885-2006(99)00017-4

Duncan, G. J., \& Magnuson, K. (2013). Investing in preschool programs. Journal of Economic Perspectives, 27, 109-132. https://doi.org/10.1257/jep.27.2.109

Ejrnæs, M., \& Kunze, A. (2013). Work and wage dynamics around childbirth. Scandinavian Journal of Economics, 115, 856-877. https://doi.org/10.1111/sjoe.12025

Elango, S., Garcia, J. L., Heckman, J. J., \& Hojman, A. (2015). Early childhood education. IZA Discussion Paper No. 9476.

European Commission. (2015). The 2015 ageing report. Economic and budgetary projections for the $28 \mathrm{EU}$ Member States (2013-2060) (Vol. 3). European Economy.

European Commission, EACEA, Eurydice, \& Eurostat. (2014). Key data on Early Childhood Education and Care in Europe. Eurydice and Eurostat Report. Luxembourg: Publications Office of the European Union. https://doi. org/10.1080/1350293x.2015.1043814

Eurostat. (2002). Structure of earnings survey: annual earnings. Retrieved from http://ec.europa.eu/eurostat/da ta/database

Eurostat. (2006). Structure of earnings survey: annual earnings. Retrieved from http://ec.europa.eu/eurostat/da ta/database 
Eurostat. (2010). Structure of earnings survey: annual earnings. Retrieved from http://ec.europa.eu/eurostat/da ta/database

Eurostat. (2014). Structure of earnings survey: annual earnings. Retrieved from http://ec.europa.eu/eurostat/da ta/database

Eurostat. (2016). Formal childcare by age group and duration. Retrieved from http://ec.europa.eu/eurostat/data/da tabase

Felfe, C. (2012). The motherhood wage gap: What about job amenities? Labour Economics, 19, 59-67. https://doi. org/10.1016/j.labeco.2011.06.016

Felfe, C., Nollenberger, N., \& Rodríguez-Planas, N. (2015). Can't buy mommy's love? Universal childcare and children's long-term cognitive development. Journal of Population Economics, 28, 393-422. https://doi.org/ $10.1007 / \mathrm{s} 00148-014-0532-x$

García, J. L., Heckman, J. J., Leaf, D. E., \& Prados, M. J. (2016). The life-cycle benefits of an influential early childhood program. NBER Working Paper No. 22993. https:/ / doi.org/10.3386/w22993

Gash, V. (2009). Sacrificing their careers for their families? An analysis of the penalty to motherhood in Europe. Social Indicators Research, 93, 569-586. https://doi.org/ 10.1007/s11205-008-9429-y

Gormley, W. T., Gayer, T., Phillips, D., \& Dawson, B. (2005). The effects of universal Pre-K on cognitive development. Developmental Psychology, 41, 872-884. https:/ / doi.org/10.1037/0012-1649.41.6.872

Haider, S., \& Solon, G. (2006). Life-cycle variation in the association between current and lifetime earnings. American Economic Review, 96, 1308-1320. https://doi. org/10.1257/aer.96.4.1308

Hanushek, E. A., Schwerdt, G., Wiederhold, S., \& Woessmann, L. (2015). Returns to skills around the world: Evidence from PIAAC. European Economic Review, 73, 103130. https://doi.org/10.1016/j.euroecorev.2014.10.006

Havnes, T., \& Mogstad, M. (2011a). Money for nothing? Universal child care and maternal employment. Journal of Public Economics, 95, 1455-1465. https://doi.org/10. 1016/j.jpubeco.2011.05.016

Havnes, T., \& Mogstad, M. (2011b). No child left behind: Subsidized child care and children's long-run outcomes. American Economic Journal: Economic Policy, 3, 97-129. https://doi.org/10.1257/pol.3.2.97

Heckman, J. J., Moon, S. H., Pinto, R., Savelyev, P. A., \& Yavitz, A. (2010). The rate of return to the HighScope Perry Preschool Program. Journal of Public Economics, 94, 114-128. https:/ / doi.org/10.1016/j.jpubeco.2009.11.001

Jaumotte, F. (2003). Female labour force participation: Past trends and main determinants in OECD countries. OECD Working Paper No. 376.

Karoly, L. A. (2016). The economic returns to early childhood education. The Future of Children, 26, 37-55. https:/ / doi.org/10.1353/foc.2016.0011

Karoly, L. A., \& Bigelow, J. H. (2005). The economics of investing in universal preschool education in California. Santa Monica, CA: RAND.
Kunze, A. (2002). The timing of careers and human capital depreciation. IZA Discussion Paper. No. 509, Bonn, Germany.

Lin, D., Lutter, R., \& Ruhm, C. J. (2016). Cognitive performance and labor market outcomes. IZA Discussion Paper No. 10075.

Lynch, R. G. (2004). Exceptional returns: Economic, fiscal, and social benefits of investing in early childhood development. Washington, DC: Economic Policy Institute.

Lynch, R. G. (2007). Enriching children, enriching the nation: Public investment in high-quality prekindergarten. Washington, DC: Economic Policy Institute.

Lynch, R., \& Vaghul, K. (2015). The benefits and costs of investing in early childhood education. The fiscal, economic, and societal gains of a universal prekindergarten program in the United States, 2016-2050. Washington, DC: Washington Center for Equitable Growth.

Melhuish, E., Ereky-Stevens, K., Petrogiannis, K., Ariescu, A., Penderi, E., Rentzou, K., . . . Leseman, P. (2015). A review of research on the effects of Early Childhood Education and Care (ECEC) upon child development. CARE project research report. Retrieved from http://ecec-care. org/resources/publications/

Mills, M., Tsang, F., Präg, P., Ruggeri, K., Miani, C., \& Hoorens, S. (2014). Gender equality in the workforce: Reconciling work, private and family life in Europe. European Commission. https: / / doi.org/10.2838/54302

Mincer, J., \& Ofek, H. (1982). Interrupted work careers: Depreciation and restoration of human capital. Journal of Human Resources, 17, 3-24. https://doi.org/10.2307/ 145520

Mulligan, C. (1999). Galton versus the human capital approach to inheritance. Journal of Political Economy, 107, S184-S224. https:/ / doi.org/10.1086/250108

Murnane, R., Willett, J., Duhaldeborde, Y., \& Tyler, J. H. (2000). How important are the cognitive skills of teenagers in predicting subsequent earnings? Journal of Policy Analysis and Management, 19, 547-568. https://doi. org/10.1002/1520-6688(200023)19:4\%3C547:AID-

PAM2\%3E3.0.CO;2-\%23

Nollenberger, N., \& Rodríguez-Planas, N. (2015). Fulltime universal childcare in a context of low maternal employment: Quasi-experimental evidence from Spain. Labour Economics, 3, 124-136. https://doi.org/10.1016/ j.labeco.2015.02.008

Nores, M., Belfield, C. R., Barnett, W. S., \& Schweinhart, L. (2005). Updating the economic impacts of the High/ Scope Perry Preschool Program. Educational Evaluation and Policy Analysis, 27, 245-261. https://doi.org/10. 3102/01623737027003245

OECD. (2011). Education at a glance: OECD indicators. Paris, France: OECD. https://doi.org/10.1002/berj.3120

OECD. (2017a). Public spending on childcare and early education. OECD family database. Retrieved from http:// www.oecd.org/els/family/database.htm

OECD. (2017b). Starting Strong V. Transitions from Early Childhood Education and Care to Primary Education. Paris, France: OECD. https://doi.org/10.1787/25216031. 
OECD. (2016a). Average annual wages-Dataset. Retrieved from http://stats.oecd.org/

OECD. (2016b). Tax database, Table I.5. Average personal income tax and social security contribution rates on gross labour income. Retrieved from http://stats.oecd.org/

Palacios, J., Lera, M. J., \& Oliva, A. (1995). Quality of child care in Spain. In W. E. Fthenakis \& M. R. Textor (Eds.), Quality of child care: International perspectives (pp. 191-199). Berlin, Germany: Beltz.

Reynolds, A. J., \& Ou, S.-R. (2011). Paths of effects from preschool to adult well-being: A confirmatory analysis of the Child-Parent Center Program. Child Development, 82, 555582. https:/ /doi.org/10.1111/j.1467-8624.2010.01562.x

Reynolds, A. J., Temple, J. A., Robertson, D. L., \& Mann, E. A. (2002). Age 21 cost-benefit analysis of the Title I Chicago Child-Parent Centers. Educational Evaluation and Policy Analysis, 24, 267-303. https://doi.org/10. 3102/01623737024004267

Reynolds, A. J., Temple, J. A., White, B. A. B., Ou, S.-R., \& Robertson, D. L. (2011). Age 26 cost-benefit analysis of the Child-Parent Center Early Education Program. Child Development, 82, 379-404. https://doi.org/10. 1111/j.1467-8624.2010.01563.x

Rogero-García, J., \& Andrés-Candelas, M. (2014). Family and state spending on education in Spain: Differences between public and publicly-funded private educational institutions. Revista Española de Investigaciones Sociológicas, 147, 121-132. https:/ /doi.org/10.5477/cis/reis.147.121

Schönberg, U., \& Ludsteck, J. (2014). Expansions in maternity leave coverage and mothers' labor market outcomes after childbirth. Journal of Labor Economics, 32, 469-505. https://doi.org/10.1086/675078

Spivey, C. (2005). Time off at what price? The effects of career interruptions on earnings. Industrial and Labor Relations Review, 59, 119-140. https://doi.org/10.1177/ 001979390505900107
Temple, J. A., \& Reynolds, A. J. (2007). Benefits and costs of investments in preschool education: Evidence from the Child-Parent Centers and related programs. Economics of Education Review, 26, 126-144. https://doi. org/10.1016/j.econedurev.2005.11.004

Tietze, W., Hundertmark-Mayser, J., \& Rossbach, H. (1999). European child care and education study: School-age assessment of child development: Long-term impact of preschool experiences on school success and family-school relationships. Final report for work package \#2. Submitted to the European Union DG XII: Science, Research and Development RTD Action: Targeted Socio-Economic Research.

Van Huizen, T., \& Plantenga, J. (2015). Universal child care and children's outcomes: A meta-analysis of evidence from natural experiments. USE Discussion Paper No. 15-13.

WSIPP. (2014). Early childhood education for low-income students: A review of the evidence and benefit-cost analysis. Olympia, WA: Washington State Institute for Public Policy.

\section{Supporting Information}

Additional supporting information may be found in the online version of this article at the publisher's website:

Appendix S1. Calculation of the Treatment Effect

Appendix S2. Calculation of the Costs Per Child Appendix S3. Calculation of the Returns to Literacy Skills

Appendix S4. Long-Term Maternal Earnings Gains

Appendix S5. Sensitivity Analysis 